ORIGINAL ARTICLE

\title{
Evaluation of the protective effectiveness of gloves from occupational exposure to 2-methoxyethanol using the biomarkers of 2-methoxyacetic acid levels in the urine and plasma
}

\author{
H-Y Chang, C-C Lin, T-S Shih, H Chan, J-S Chou, Y-S Huang
}

Occup Environ Med 2004;61:697-702. doi: 10.1136/oem.2003.011171

See end of article for authors' affiliations

Correspondence to: Dr T-S Shih, Institute of Occupational Safety and Health, Council of Labor Affairs, No. 99, Lane 407, Heng-Ke Rd, Shijr City, Taipei, Taiwan 221, Republic of China; stone@ mail.iosh.gov.tw

Accepted 14 February 2004

\begin{abstract}
Aims: To evaluate the protective effectiveness of gloves from occupational exposure to 2-methoxyethanol (2-ME); and to examine the association of 2-methoxyacetic acid (MAA) in urine and plasma collected simultaneously from low 2-ME exposure and high 2-ME exposure workers in a semiconductor copper laminate circuit board manufacturing plant.

Methods: Eight hour time weighted breathing zone monitoring was performed to verify the 2-ME exposure classification between workers in regular and special operations. Urine and plasma samples were simultaneously collected from 74 exposed and 80 non-exposed workers. MAA concentrations in the urine (UMAA) and plasma (PMAA) were measured using previously published methods. Three types of gloves worn by workers (cotton, rubber, and no gloves) were recorded by direct observations in the workplace and validated by person-to-person interview. Protective effectiveness indices (PEI) were used to evaluate the glove effectiveness.

Results: There was no detectable 2-ME/MAA in the air, or in urine and plasma samples in non-exposed workers. The average UMAA and PMAA in special operations were $72.63 \mathrm{mg} / \mathrm{g} \mathrm{Cr}$. and $29.72 \mathrm{mg} / \mathrm{l}$, significantly higher than values in regular operations $(5.44 \mathrm{mg} / \mathrm{g} \mathrm{Cr}$. and $2.58 \mathrm{mg} / \mathrm{l}$, respectively). PMAA showed satisfactory correlation to UMAA in all participants from both regular and special operations. The rubber gloves provided significant reduction in 2-ME uptake, whereas cotton gloves provided little protection with fluctuating effectiveness, based on PEI estimates.

Conclusions: PMAA, similar to UMAA, could serve as a specific biomarker for 2-ME exposure. Wearing impermeable rubber gloves during high risk tasks can reduce major 2-ME exposure. Other improvements, including engineering control, should be provided to diminish worker exposure to 2-ME in occupational environments.
\end{abstract}

2 -Methoxyethanol (2-ME) is an important solvent widely used as the de-icing additive in military jet fuel and in the semiconductor laminate circuit board manufacturing industries. ${ }^{1}$ Exposure to 2-ME adversely affects the reproductive, ${ }^{23}$ developmental, ${ }^{24}$ and haematological $^{25}{ }^{6}$ systems. In mammals, administered 2-ME is mainly metabolised into 2-methoxyacetic acid (MAA) via alcohol dehydrogenase and aldehyde dehydrogenase..$^{7-9}$ The metabolite (MAA), but not the parent compound (2-ME), is the responsible toxicant causing damage to the Sertoli cell culture $^{8}$ and whole embryo culture. ${ }^{10}$ Therefore, MAA is suggested to be the proximate toxicant in 2-ME exposure. $^{1}{ }^{10-12}$ Urinary MAA levels showed satisfactory correlation with integrated exposure to 2 -ME both in human volunteer studies ${ }^{13}{ }^{14}$ and in our recent field studies. ${ }^{15} 16$ Moreover, MAA has been found to be the major metabolite in the urine in animals and humans occupationally or experimentally exposed to $2-\mathrm{ME}^{7}{ }^{9}$ but was not detected in non-exposed workers. Therefore, UMAA has been recommended as a biomarker for occupational exposure to 2-ME by the United States National Institute for Occupational Safety and Health (NIOSH) and the American Conference for Governmental Industrial Hygienists (ACGIH). ${ }^{17}$ However, toxicokinetic studies have shown that toxicant blood concentrations and their metabolites usually provide more direct and valuable information than concentrations in urine samples. Until now, however, MAA concentrations in human blood samples have not been reported in the literature. However, MAA in urine, which represents the amount excreted from the body, might not necessarily correlate well with the remaining MAA in the body. MAA in the blood could be more relevant to its toxicity than its urine concentration. Therefore, it could be of interest to study the relation of UMAA and plasma MAA concentrations in samples simultaneously collected from 2-ME exposed workers.

A number of epidemiological studies and case reports have suggested that skin absorption might be an important 2-ME exposure route. ${ }^{18-20}$ Johanson and Boman suggested that the skin vapour absorption of 2-ME could be a more significant exposure route compared with respiratory exposure. ${ }^{21}$ This has been validated in our recent human volunteer study which reported skin uptake doses during four hour single arm 25 ppm 2-ME exposure were higher than those during 5 ppm inhalation exposure for eight hours. ${ }^{22}$ The absorption rate for skin liquid contact is far greater than that for skin vapour exposure. ${ }^{23}$ In summary, these studies, together with those of Kezic and colleagues, ${ }^{14}$ have shown that skin absorption, through both liquid contact and vapour absorption, is the major 2-ME exposure route. The protection

Abbreviations: 2-ME, 2-methoxyethanol; GM, geometric mean; GSD, geometric standard deviation; MAA, 2-methoxyacetic acid; PMAA, plasma MAA; UMAA, urine MAA 
Main messages

- PMAA, as UMAA, is a specific biomarker for occupational exposure to 2-ME.

- Wearing impermeable rubber gloves during high risk tasks can reduce major 2-ME exposure.

- The protection from 2-ME exposure by only wearing the appropriate gloves is not complete. Other improvements, including engineering control, should be provided to diminish worker exposure to $2-M E$ in occupational environments.

measures from skin exposure become an important issue for workers occupationally exposed to 2-ME. The protective effectiveness of gloves against skin exposure to 2-ME was also evaluated in this study because wearing gloves is the most popular way to protect skin from exposure in occupational environments.

\section{MATERIALS AND METHODS}

Subject recruitment and exposure characterisation

Seventy four male workers in the coating department of a semiconductor copper laminate circuit board manufacturing plant using 2-ME as the major solvent were recruited as the exposed group. Eighty non-exposed male workers in the administrative department of the same plant were chosen as the control group. All participating workers were asked not to drink alcohol, take medication, or expose themselves to other organic solvents (such as painting at home) during this study. Informed consent was given and signed by all participating workers before the study began.

Based on the intensity and frequency of exposure to 2-ME, the 74 exposed subjects were further categorised into two groups: regular operations and special operations. The regular operations included unwinding, splicing, accumulation, dipping, oven heating, edge trimming, rewinding, and sheeting operations. These operations are reported to involve less exposure to 2-ME. The special operations included raw material mixing, charging, and machine cleaning, and were reported to involve more serious exposure to 2-ME. ${ }^{15}$ All exposed workers wore short sleeved work clothes. The workers used impermeable rubber gloves, cotton gloves, or no gloves. Some workers wore cotton gloves on the job because the cotton gloves provided more friction to help them switch the knots in the machines, move processing materials, and prevent their palms from being irritated by the rough materials used in manufacturing processes. In special operations, several workers wore half-elbow-length butyl rubber gloves (B131R; thickness, 17 mil; length, 14 inches; North Safety Product, USA) in tasks that exposed the hands and forearms to liquid materials containing 2-ME. These high risk liquid contact tasks, which included raw material charging, mixing, and machine cleaning, took 2-4 hours to complete for workers in special operations. Although dermal contact to liquid 2-ME was reduced, the half-elbow-length butyl rubber gloves were still inconvenient to use. Because of very limited reports purporting the protective effectiveness of the gloves from 2-ME exposure, the impermeable rubber gloves policy was only recommended, but not strictly enforced. The glove wearing status was recorded by direct observations during the field study and validated by personto-person interviews. The relative humidity in the workplaces was measured at $80-85 \%$. The ambient temperatures in regular operations and operations were, on average, $25-27^{\circ} \mathrm{C}$ and $30-33^{\circ} \mathrm{C}$, respectively. Due to the hot and humid
Policy implications

- Wearing appropriate impermeable gloves during high risk operations like mixing, charging, and machine cleaning in the 2-ME exposed environments should be enforced with the highest priority.

- The factory owner should provide other improvements, including engineering control, to diminish worker exposure to $2-M E$ in occupational environments.

environment, all workers refused to wear respirators during their work.

\section{Exposure monitoring and exposure classification validation for two operations}

To verify that the 2 -ME exposure classification among regular exposure operations (to represent low 2-ME exposure), special exposure operations (to represent high 2-ME exposure), and controls (to represent no 2-ME exposure) was valid, eight-hour time weighted average ( 8 -h TWA) personal breathing zone 2-ME monitoring was conducted for the 74 exposed workers, and 12 evenly distributed 8-h fixed-point samples were taken in the administrative department using 3M 3500 passive badges (3M Co., Model 3500, St Paul, USA) a week before biological monitoring commenced. Airborne samples were analysed using our previously published method using a gas chromatograph (Hewlett-Packard 5890 Series II, CA, USA) equipped with a flame ionisation detector. $^{24}$

\section{Biological MAA level monitoring in urine and plasma samples}

Urine and plasma samples were collected simultaneously near the end of the last workday in the week (Friday) from all participants. Urinary MAA (UMAA) was measured using a gas chromatograph equipped with an HP 7673A autosampler and a flame ionisation detector based on our previously published method..$^{25}$ Before instrumental analysis, urine samples were prepared using the following procedure: acidification with concentrated hydrogen chloride; extraction with the mixture of dichloromethane and isopropyl alcohol $(2: \mathrm{l}, \mathrm{v} / \mathrm{v})$; and esterification with trimethylsilyldiazomethane. This method provides detection and accuracy limits of $0.055 \mu \mathrm{g} / \mathrm{ml}$ and $99.0 \%$, respectively over the concentration range $0.3-200 \mu \mathrm{g} / \mathrm{ml}$ with a pooled coefficient of variation of $5.55 \%$. Urinary creatinine was analysed using the Jaffe method $^{26}$ for concentration correction. The UMAA results were expressed as $\mathrm{mg} / \mathrm{g}$ creatinine $(\mathrm{mg} / \mathrm{g} \mathrm{Cr}$.).

MAA in plasma (PMAA) were determined using a gas chromatograph/mass detector (GC/MS) equipped with an HP 7673 A autosampler using our previously published method. ${ }^{27}$ In brief, plasma samples were acidified with concentrated $\mathrm{HCl}$, then extracted with mixed methylene chloride and isopropyl alcohol $(2: 1, \mathrm{v} / \mathrm{v})$ solvents. The samples were further centrifuged at $3000 \mathrm{rpm}$ for 5 minutes prior to GC/ MS analysis. This method provides a detection limit and accuracy of $0.05 \mu \mathrm{g} / \mathrm{ml}$ and $98.2 \%$ respectively, over the concentration range $0.3-200 \mu \mathrm{g} / \mathrm{ml}$ with a pooled coefficient of variation of $4.9 \%$.

\section{Evaluation of the protective effectiveness of gloves}

The protective effectiveness of the gloves was determined using the Protective Effectiveness Index (PEI). PEI was defined by the ratios of the differences in the body burden indices (UMAA and PMAA) between those that wore no gloves (bare hands) and those that wore gloves (cotton and 
rubber) over the body burden indices (UMAA and PMAA) for those that wore no gloves (bare hands). The equations are shown below:

$$
\begin{aligned}
& \text { Protective Effectiveness Index for UMAA }\left(\mathrm{PEI}_{\mathrm{U}}\right) \\
& =\frac{\left(\mathrm{UMAA}_{\text {barehand }}-\mathrm{UMAA}_{\text {withglove }}\right)}{\left(\mathrm{UMAA}_{\text {barehand }}\right)} \times 100 \%
\end{aligned}
$$

Protective Effectiveness Index for PMAA $\left(\mathrm{PEI}_{\mathrm{P}}\right)$

$$
=\frac{\left(\mathrm{PMAA}_{\text {barehand }}-\mathrm{PMAA}_{\text {withglove }}\right)}{\left(\mathrm{PMAA}_{\text {barehand }}\right)} \times 100 \%
$$

\section{Statistical analysis}

The Shapiro-Wilks $\mathrm{W}$ test was performed to assess the normality of the airborne 2-ME concentrations, UMAA, and PMAA concentration distributions. The airborne 2-ME, UMAA, and PMAA concentration distributions were all shown log normally distributed. The geometric mean (GM) and geometric standard deviation (GSD) were used to present the central tendency and the degree of measurement dispersion. The $\chi^{2}$ test and Mann-Whitney $U$ test were used to determine the categorical (such as glove type) and continuous data (such as airborne 2-ME, UMAA, and PMAA) between the two groups. Linear regression and Spearman rank correlation tests were performed to evaluate the relation between UMAA and PMAA. The K-W ANOVA test was used to test whether there were significant differences among the combinations of various glove types and exposure groups. The Mann-Whitney U test was applied to test the one-by-one difference in post hoc comparison if the aforementioned K-W ANOVA showed statistical significance. The Statistica Software (Release 6.0; StatSoft Inc., OK, USA) was used for statistical analysis.

\section{RESULTS}

All measurements regarding airborne 2-ME, UMAA, and PMAA in non-exposed subjects were found to be below the detection limits, and were therefore excluded from further data analyses. All other measurements on exposed subjects were detectable. The environmental monitoring results showed that the average airborne 2-ME concentrations for the workers in special operations were 8.13 (1.62) ppm, higher than the permissible exposure limit for 2-ME in Taiwan. This was also significantly higher than the exposure level in regular operations, 2.14 (2.01) ppm ( $p<0.001)$. This indicated that the grouping criteria based on operation type was acceptable (table 1). A significant difference was found for glove type in the two operations $(\mathrm{p}<0.001)$. Workers in regular operations $(n=49)$ mostly wore no gloves $(81.6 \%)$, others wore cotton gloves $(18.4 \%)$, and no one wore rubber gloves. The highest proportion of workers in special operations $(n=25)$ wore cotton gloves $(60.0 \%)$, followed by no gloves $(28.0 \%)$. Only three workers wore impermeable rubber gloves $(12 \%)$.

Similar to the airborne 2-ME monitoring finding, both UMAA levels and PMAA levels for the workers in special operations were significantly higher than levels in regular operations $(\mathrm{p}<0.001)$. The average UMAA and PMAA concentrations for special operations were 72.63 (2.04) mg/g Cr. and 29.72 (1.95) mg/l, about thirteen-fold and twelvefold of 5.44 (3.59) $\mathrm{mg} / \mathrm{g} \mathrm{Cr}$. and 2.58 (3.64) $\mathrm{mg} / \mathrm{l}$ of that in regular operations, respectively (table 2 ). PMAA showed satisfactory correlation to UMAA in all participants, both low exposed (regular operations) and high exposed groups (special operations). The correlation coefficients for all workers, regular operations, and special operations, were $0.91,0.79$, and 0.89, respectively. All levels reached statistical significance $(\mathrm{p}<0.001)$, suggesting a proportional relation between these two biomarkers (fig 1 ). Moreover, the slope estimates of $0.88,0.80$, and 0.82 were relatively close to each other for all participants, low exposed, and high exposed groups. This suggested the relations of PMAA to UMAA were relatively constant over a wide spectrum of exposed conditions.

When the dermal absorption evaluation on workers using

\begin{tabular}{|c|c|c|c|c|}
\hline & $\begin{array}{l}\text { Regular } \\
(n=49)\end{array}$ & $\begin{array}{l}\text { Special } \\
(n=25)\end{array}$ & $\begin{array}{l}\text { Total } \\
(n=74)\end{array}$ & $\begin{array}{l}\text { Regular v special } \\
\text { p value }\end{array}$ \\
\hline \multicolumn{5}{|c|}{ Airborne 2-ME (ppm) } \\
\hline GM (GSD) & $2.14(2.01)$ & $8.13(1.62)$ & $3.31(2.45)$ & \multirow[t]{2}{*}{$<0.001^{*}$} \\
\hline Range & $0.57-9.28$ & $3.18-15.64$ & $0.57-15.64$ & \\
\hline \multicolumn{5}{|c|}{ Glove type (frequency, \%) } \\
\hline No gloves & $40(81.6 \%)$ & 7 (28.0\%) & $47(63.5 \%)$ & \multirow{3}{*}{$<0.001 \dagger$} \\
\hline Cotton & $9(18.4 \%)$ & $15(60.0 \%)$ & $24(32.4 \%)$ & \\
\hline Rubber & $0(0.0 \%)$ & $3(12.0 \%)$ & $3(4.1 \%)$ & \\
\hline
\end{tabular}
personal protection equipment was performed, no significant differences were found by either UMAA or PMAA in regular

Table 2 Concentrations of urinary MAA (UMAA) and plasma MAA (PMAA) for the workers in the two groups

\begin{tabular}{lllll} 
& $\begin{array}{l}\text { Regular } \\
(\mathbf{n}=49)\end{array}$ & $\begin{array}{l}\text { Special } \\
(\mathbf{n}=\mathbf{2 5})\end{array}$ & $\begin{array}{l}\text { Total } \\
(\mathbf{n}=74)\end{array}$ & $\begin{array}{l}\text { Regular v special } \\
\mathbf{p} \text { value* }\end{array}$ \\
\hline $\begin{array}{l}\text { UMAA (mg/g Cr.) } \\
\text { GM (GSD) }\end{array}$ & $5.44(3.59)$ & $72.63(2.04)$ & $13.05(5.27)$ & $<0.001$ \\
$\begin{array}{l}\text { Range } \\
\text { PMAA (mg/l) }\end{array}$ & $0.52-40.57$ & $16.39-178.00$ & $0.52-178.00$ & \\
$\begin{array}{l}\text { GM (GSD) } \\
\text { Range }\end{array}$ & $2.58(3.64)$ & $29.72(1.95)$ & $5.90(5.01)$ & $<0.001$ \\
\hline *B Mann-Whitney U test. & $0.50-45.87$ & $5.03-61.93$ & $0.50-61.93$ & \\
\end{tabular}



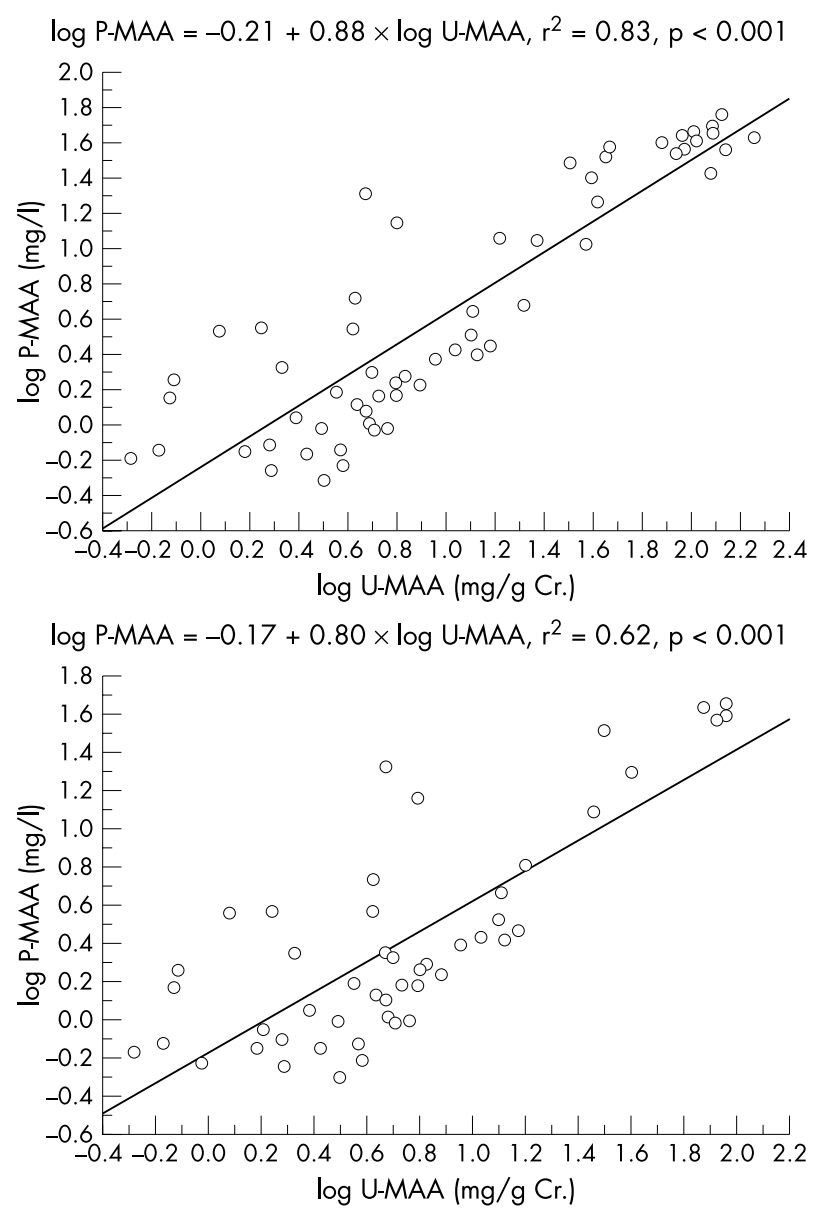

$\log$ P-MAA $=-0.06+0.82 \times \log$ U-MAA, $r^{2}=0.79, p<0.001$

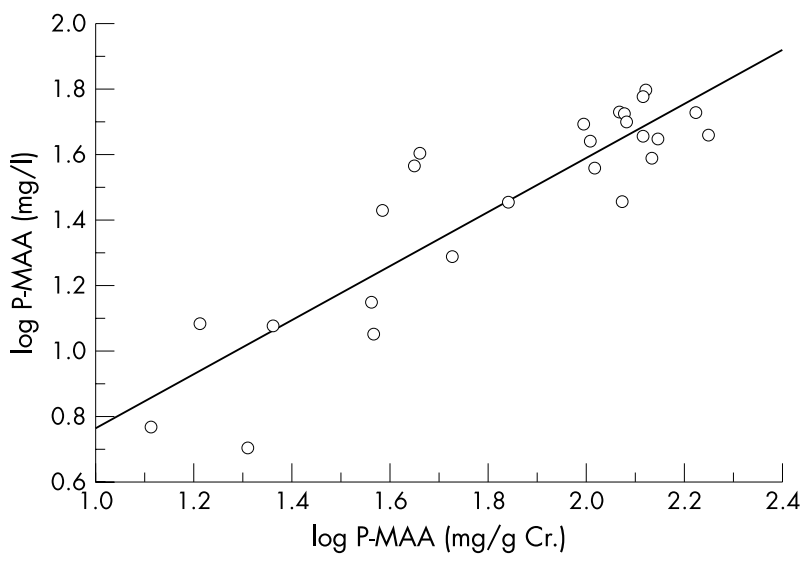

Figure 1 MAA concentration regressions in urine (UMAA) and in plasma (PMAA). Top: all participants $(n=74)$; middle: workers in regular operations $(n=49)$; bottom: workers in special operations $(n=25)$. All regression coefficients showed statistical significance $(p<0.001)$.

operation workers (fig 2). The significant differences, however, were found in the comparisons between bare hand and rubber gloves $(p=0.05)$, and cotton gloves and rubber gloves $(p=0.01)$ based on UMAA comparisons. A difference between cotton gloves and rubber gloves $(p=0.01)$, and a marginal difference between bare hands and rubber gloves $(p=0.09)$ was found based on PMAA comparisons for special operations. The results suggested that the protective effectiveness of gloves only showed in highly exposed conditions (that is, special operations). Only the rubber gloves were effective enough to reduce the internal 2-ME exposure dose. In general, cotton gloves showed little and fluctuating effectiveness $(-36.8 \%$ to $11.0 \%)$ in reducing the total $2-\mathrm{ME}$ exposure body burden compared with wearing no gloves (table 3). Rubber gloves provided more than two thirds (68.9\% to $74.8 \%$ ) of the effectiveness with respect to UMAA and PMAA reduction. Following glove effectiveness, the ratios of UMAA to PMAA were further investigated according to glove type. The average ratios of UMAA to PMAA for no gloves (bare hands, $n=47)$, cotton gloves $(n=24)$, and rubber gloves $(\mathrm{n}=3)$ were $0.78,0.80$, and 0.97 , respectively, and no significant differences were found among them (fig 3). The ratio estimates were quite close to the slope estimate of 0.88 obtained from fig 1 , indicating the relations of PMAA to UMAA were relatively stable in various glovetype conditions. More conservative interpretation on the ratio estimate for rubber glove subgroup should be noted because of only three subjects in the subgroup. Although all workers in the factory were exclusively recruited in the study, this study was unable to evaluate the combined effect of glove type (no gloves, cotton gloves, and rubber gloves) and exposure levels (regular operations and special operations) on the ratios of PMAA to UMAA owing to insufficient sample size.

\section{DISCUSSION}

No detectable MAA was found in urine and plasma samples in unexposed administrative subjects. All urine and plasma samples collected from the low exposed (regular operations) and high exposed groups (special operations) provided quantifiable MAA. Moreover, the slope estimates in the regression models of PMAA to UMAA were relatively close to each other over a wide spectrum of exposed conditions (fig 1 ), and PMAA:UMAA ratios were relatively stable in various glove-type conditions (fig 3). Taken together, these findings suggested that UMAA and PMAA are specific biomarkers for occupational exposure to 2-ME.

Blood is an essential transport vehicle for chemicals and their metabolites in the body. Lowry and colleagues reported that relatively small inter-individual variations of blood components affect blood levels of most determinants for blood monitoring. ${ }^{28}$ Therefore, blood has long been considered a central compartment in most pharmacokinetic and toxicokinetic studies. From our previous studies, UMAA was shown to be a good biomarker for occupational exposure to 2ME using one-day exposure and one-week exposure. ${ }^{15} 1625$ In this study, PMAA showed satisfactory correlation with UMAA for all participants, with both low and high exposure (fig 1). To the best of our knowledge, this is the first study to examined MAA concentrations in urine and plasma simultaneously. The overdose exposure to 2-ME was documented to cause haematological manifestations. ${ }^{56}$ It is generally accepted that the determination of toxicants in biological media related more to the target organ (plasma in this case) could be more relevant to health effects. The overall satisfactory correlation between UMAA and PMAA shown in this study provided affirmative evidence that UMAA reflects the excretory levels of 2-ME exposure and is proportional to the residual levels of active toxicants remaining in the body. Moreover, a possible scientific basis for the findings in our previous studies that haematological defects correlated well with UMAA among workers occupationally exposed to 2-ME was presented. ${ }^{29} 30$

Nearly 200 chemical hazards in the threshold limit value booklet published by ACGIH ${ }^{17}$ have been marked with "skin notations", implying possible skin absorption. However, for half a century, skin absorption has been largely ignored in exposure assessment, regulation setting, and especially, hazard control. As occupational health standards in regulating 

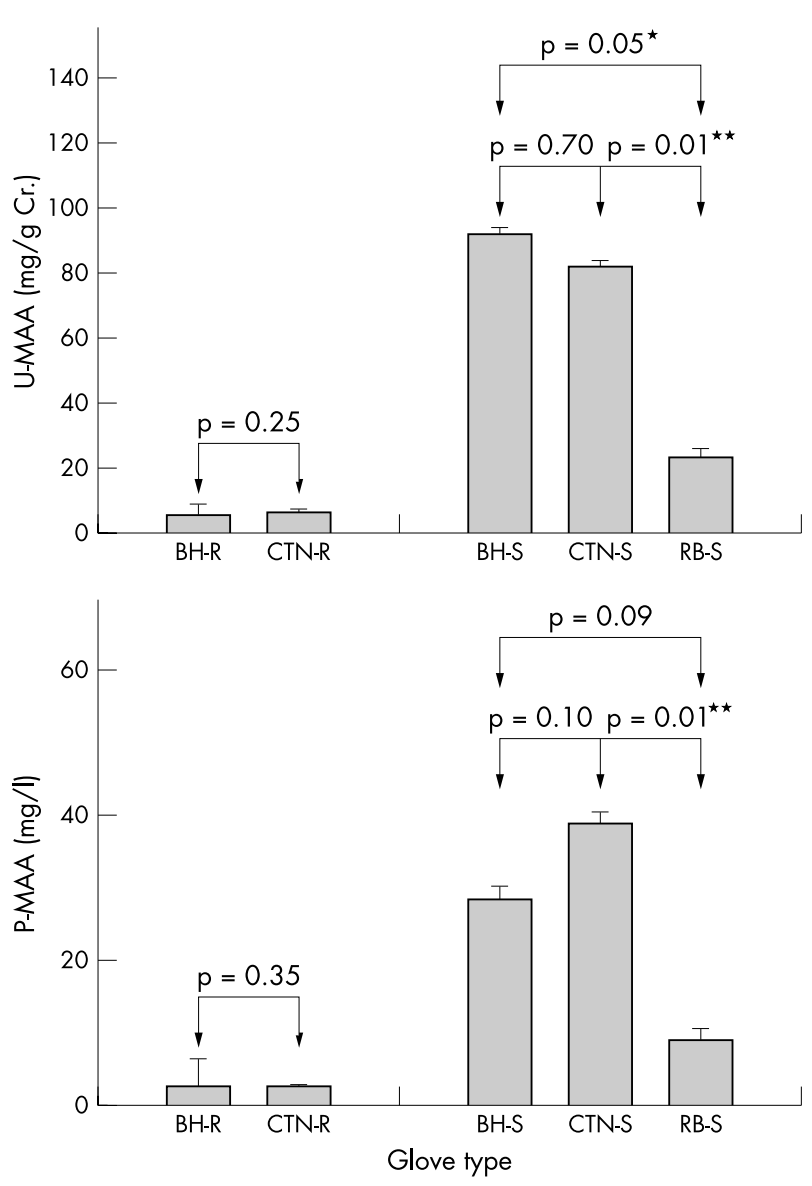

Figure 2 Levels of UMAA and PMAA in regular operations and special operations based on the type of gloves worn. R, regular operations; $S$, special operations; $B H$, bare hands; $C T N$, cotton gloves; $R B$, rubber gloves. Significant differences $(p<0.001)$ in either UMAA or PMAA were found among five groups by K-W ANOVA test. The MannWhitney $U$ test was applied for one-by-one combination test within the same group; $p$ values are shown.

airborne contaminants become increasingly stringent, the contribution of skin absorption will be expected to become increasingly important. The absorption of 2-ME through the skin could be more significant in comparison with that through the respiratory tract. ${ }^{18-23}$ Protection from skin exposure to such a strong skin permeable chemical is especially important. In comparison with the metabolite levels in the low exposure group without gloves, we found approximately 3-4-fold and 12-13-fold higher levels of metabolites in the high exposure group with rubber gloves and without gloves, respectively (fig 2 ). This showed that workers wearing impermeable rubber gloves exhibited a two thirds reduction in 2-ME exposure to the body (table 3). On the other hand, cotton gloves provided little protection or even aggravated the exposure effects. This study, therefore, has shown that wearing gloves can effectively reduce the exposure to skin permeable chemicals in an occupational environment. Equally importantly, wearing the appropriate gloves (rubber gloves in this case), can prevent exposure to the chemical via the dermal route. Many types of rubber gloves have been produced, and their performance in chemical hazard prevention has exhibited substantial discrepancies. Butyl rubber, used in this study, has shown the highest protective effectiveness against glycol-ether derivatives. ${ }^{31}$ We therefore suggest that wearing appropriate impermeable gloves during high risk operations such as
Table 3 Protective Effectiveness Indices for UMAA (PEl $U$ ) and PMAA (PEIP) for cotton gloves (CTN) and rubber gloves $(\mathrm{RB})$ in contrast to bare hands $(\mathrm{BH})$ in two exposure groups

\begin{tabular}{|c|c|c|c|}
\hline & \multirow{2}{*}{$\begin{array}{l}\text { Regular } \\
\text { CTN }(n=9) v \text { BH } \\
(n=40)\end{array}$} & \multicolumn{2}{|l|}{ Special } \\
\hline & & $\begin{array}{l}\mathrm{CTN}(\mathrm{n}=15) v \mathrm{BH} \\
(\mathrm{n}=7)\end{array}$ & $\begin{array}{l}\mathrm{RB}(\mathrm{n}=3) \vee \mathrm{BH} \\
(\mathrm{n}=7)\end{array}$ \\
\hline $\begin{array}{l}\text { PElu } \\
\text { PElP }\end{array}$ & $\begin{array}{r}-16.86 \\
1.93\end{array}$ & $\begin{array}{r}10.98 \\
-36.82\end{array}$ & $\begin{array}{l}74.76 \\
68.90\end{array}$ \\
\hline
\end{tabular}

PEl $_{U}$ : Protection Effectiveness Index for UMAA =

$$
\frac{\left(\mathrm{UMAA}_{\text {barehand }}-\mathrm{UMAA}_{\text {withglove }}\right)}{\left.\mathrm{UMAA}_{\text {barehand }}\right)} \times 100 \%
$$

PElp: Protection Effectiveness Index for PMAA =

$$
\frac{\left(\mathrm{PMAA}_{\text {barehand }}-\mathrm{PMAA}_{\text {withglove }}\right)}{\text { PMAA } \left._{\text {barehand }}\right)} \times 100 \%
$$

mixing, charging, and machine cleaning should be enforced with the highest priority. The effectiveness of wearing appropriate gloves against 2-ME exposure, however, cannot be overstated. The average UMAA and PMAA concentrations for those wearing rubber gloves among high exposure (special operations) workers were 23.19 (1.53) mg/g Cr. and $8.81(1.63) \mathrm{mg} / \mathrm{l}$, respectively, both significantly higher than the 5.08 (4.04) mg/g Cr. and 2.59 (4.41) mg/l $(\mathrm{p}<0.001$ for both tests) for those wearing no gloves in the low exposure group (regular operations) (fig 2). The nearly fourfold difference in metabolite data between special operation and regular operation workers, almost the same order of magnitude difference in their corresponding air 2-ME concentrations (table 1), probably reflects a greater potential for exposure by all routes, and suggests that protection from only wearing the appropriate gloves is not complete. Other improvement measures, including engineering control, should be provided to reduce worker exposure to 2-ME in occupational settings.

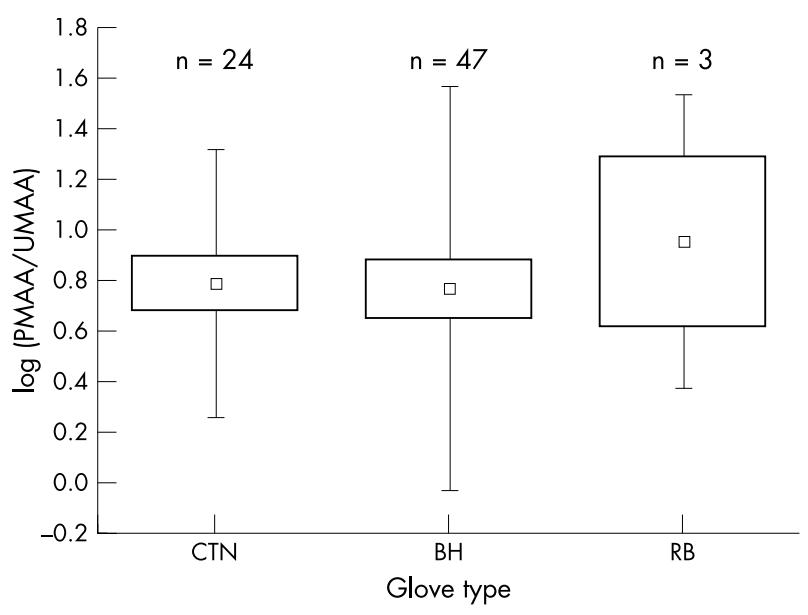

Figure 3 Comparisons (box and whisker plots) for the ratios PMAA:UMAA among the three glove-type subgroups: CTN, cotton gloves; $\mathrm{BH}$, bare hands; RB, rubber gloves. No significant differences were found by K-W ANOVA test. Central square = mean; outer box = standard error; upper and lower boundary= standard deviation. 


\section{ACKNOWLEDGEMENTS}

We are indebted to Dr Chung-Wen Chen from Mithra Bioindustry Co. Ltd for his participation, discussion, and technical help. This work was supported by the Institute of Occupational Safety and Health Council of Labor Affairs, Executive Yuan, Taiwan, Republic of China.

\section{Authors' affiliations}

H-Y Chang, Department of Environmental and Occupational Health, College of Medicine, National Cheng Kung University, Tainan, Taiwan, ROC

C-C Lin, Labor Safety and Health Directorate, Council of Labor Affairs, No. 83, Yen-Ping N. Rd, Taipei, Taiwan, Republic of China T-S Shih, J-S Chou, Institute of Occupational Safety and Health, Council of Labor Affairs, No. 99, Lane 407, Heng-Ke Rd, Shijr City, Taipei, Taiwan 221, Republic of China H Chan, Mithra Bioindustry Co., Ltd 7F, No. 102, Sec. 1, Hsin-Tai 5th $\mathrm{Rd}$, Hsichih, Taipei County, Taiwan, Republic of China Y-S Huang, Center for Environmental, Safety and Health Technology, Industrial, Technology Research Institute, Hsin Chu, Taiwan, Republic of China

\section{REFERENCES}

1 National Institute of Occupational Safety and Health. Criteria for a recommended standard-occupational exposure to ethylene glycol monomethyl ether, ethylene glycol monoethyl ether, and their acetates. Publication number 91-119. Cincinnati, OH: NIOSH, 1991.

2 Nagano K, Nakayama E, Oobayashi $H$, et al. Experimental studies on toxicity of ethylene glycol monomethyl ether in Japan. Environ Health Perspect 1984;57:75-84.

3 Welch LS, Schrader SM, Turner TW, et al. Effects of exposure to ethylene glycol ethers on shipyard painters: II. Male reproduction. Am J Ind Med 1988;14:509-26.

4 Wickramaratne GA. The teratogenic potential and dose-response of dermally administered ethylene glycol monomethyl ether estimated in rats with the Chernoff-Karlock assay. J Appl Toxicol 1986;6:165-6.

5 Larese F, Fiorito A, Zotti RD. The possible haematological effects of glycol monomethyl ether in a frame factory. Br J Ind Med 1992;49:131-3.

6 Welch LS, Cullen MR. Effects of exposure to ethylene glycol ethers on shipyard painters: III. Hematological effects. Am J Ind Med 1988;14:527-36.

7 Miller RR, Hermann EA, Langvardt PW, et al. Comparative metabolism and disposition of ethylene glycol monomethyl ether and propylene glycol monomethyl ether in male rats. Toxicol Appl Pharmacol 1983;67:229-37.

8 Moss EJ, Thomas LV, Cook MW, et al. The role of metabolism in 2-methoxy ethanol induced testicular toxicity. Toxicol Appl Pharmacol 1985;79:480-9.

9 Groeseneken D, Veulemas H, Masschelein R, et al. Experimental human exposure to ethylene glycol monomethyl ether. Int Arch Occup Environ Health 1989;61:243-7.

10 Yonemoto J, Brown NA, Webb M. Effects of dimethoxyl phthalate, monomethoxyethyl phthalate, 2-methoxyethanol and methoxyacetic acid on post-implantation rat embryos in culture. Toxicol Lett 1984;21:97-102.
11 Miller RR, Carreon RE, Young JT, et al. Toxicity of methoxyacetic acid in rats. Fund Appl Toxicol 1982;2:158-60.

12 Sleet RB, Greene JA, Welsch F. The relationship of embryotoxicity to disposition of 2-methoxyethanol in mice. Toxicol Appl Pharmacol 1988;93:195-207.

13 Groeseneken D, Veulemas H, Masschelein R, et al. Experimental human exposure to ethylene glycol monomethyl ether. Int Arch Occup Environ Health 1989;61:243-7.

14 Kezic S, Mahieu K, Monster A, et al. Dermal absorption of vaporous and liquid 2-methoxyethanol and 2-ethoxyethanol in volunteers. Occup Environ Med 1997;54:38-43.

15 Shih TS, Liou SH, Chen CY, et al. Correlation between urinary 2-methoxy acetic acid and exposure of 2-methoxy ethanol. Occup Environ Med 1999;56:674-8.

16 Shih TS, Liou SH, Chen CY, et al. Urinary 2-methoxy acetic acid accumulation in response to 2-methoxy ethanol exposure. Arch Environ Health 2001;56:20-5.

17 American Conference of Governmental Industrial Hygienists (ACGIH). TLVs threshold limit values for chemical substances and physical agents and biological indices (BEIs). Cincinnati, OH: ACGIH, 1998:97-101.

18 Larese F, Fiorito A, Zotti RD. The possible haematological effects of glycol monomethyl ether in a frame factory. $\mathrm{Br} J$ Ind Med 1992:49:131-3.

19 Cohen R. Reversible subacute ethylene glycol monomethyl ether toxicity associated with microfilm production: 1 case report. Am J Ind Med 1984;6:441-6.

20 Ohi G, Wegman DH. Transcutaneous ethylene glycol monomethyl ether poisoning in the work setting. J Occup Med 1978;20:675-6.

21 Johanson G, Boman A. Percutaneous absorption of 2-butoxy ethanol vapor in human subjects. Br J Ind Med 1991;48:788-92.

22 Shih TS, Wang PY, Chen CY, et al. Measurement of percutaneous uptake of 2methoxy ethanol vapor in humans. J Occup Environ Med 2000;42:475-82.

23 Dugard PH, Walker M, Mawdsley SJ, et al. Absorption of some glycol ethers through human skin in vitro. Environ Health Perspect 1984;57:193-7.

24 Shih TS, Chen CY, Cheng Rl, et al. Field evaluation of a passive sampler for 2methoxy ethanol exposure assessment. Int Arch Occup Environ Health 2000;73:98-104.

25 Shih TS, Chou JS, Chen CY, et al. Improved method to measure urinary alkoxy acetic acids. Occup Environ Med 1999;56:460-7.

26 Henry RJ, Cannon DC, Winkleman JW. Automated determination of serum and urine creatinine. In: Henry RJ, Cannon DC, Winkleman JW, eds. Clinical chemistry, principles and techniques. New York: Harper and Row, 1974:552-5.

27 Shih TS, Pan RN, Chou JS, et al. Gas chromatography/mass spectrometric assay for 2-methoxy ethanol and 2-methoxy acetic acid in human plasma and its application to pharmacokinetic study. Chromatographia 2001:54:389-93.

28 Lowry LK, Rosenberg J, Fiserova-Bergerova V. Measurements in blood. In: Topics in biological monitoring. Cincinnati, OH: ACGIH, 1995:19-24.

29 Shih TS, Hsieh AC, Liao GD, et al. Hematological effects after exposure to ethylene glycol monomethyl ether in a copper-clad laminate factory. Occup Environ Med 2000; 57:348-52.

30 Shih TS, Hsieh AC, Liao GD, et al. A follow-up study of haematological effects on workers exposed to 2-methoxy ethanol. Occup Environ Med 2003:60:130-5.

31 Zellers ET, Ke HQ, Smigiel D, et al. Glove permeation by semiconductor processing mixtures containing glycol-ether derivatives. Am Ind Hyg Assoc J 1992;53:105-16. 